\title{
Photocatalytic Removal of Xylene Vapor from Air Flow by Using Titanium Dioxide Nanoparticles Immobilized on Synthesis Type 5 Zeolite
}

\author{
Hossein Ali Rangkooy ${ }^{1}$, Atefeh Siahi Ahangar², Fereshteh Jahani2,**
}

${ }^{1}$ Assistant Professor, Environmental Technologies Research Center, Ahvaz Jundishapur University of Medical Sciences, Ahvaz, Iran, \& Department of Occupational Health Engineering, School of Health, Ahvaz Jundishapur University of Medical Sciences, Ahvaz, Iran

${ }^{2}$ M.Sc Student in Occupational Health Engineering, Jundishapour University of Medical Sciences, Ahvaz, Iran

* Corresponding Author: Fereshteh Jahani, Jundishapour University of Medical Sciences, Ahvaz, Iran. Email: jahani.f71@gmail.com

Received: 07/08/2018

Accepted: 15/09/2018

\section{How to Cite this Article:} Rangkooy HA, Siahi Ahangar A, Jahani F. Photocatalytic Removal of Xylene Vapor from Air Flow by Using Titanium Dioxide Nanoparticles Immobilized on Synthesis Type 5 Zeolite. J Occup Hyg Eng. 2018; 5(2): 39-45. DOI: 10.21859/ johe.5.2.39

\section{Abstract}

Background and Objective: Xylene is a volatile organic compound that is widely used in various industries. Xylene is hazardous not only for the environment but also for human health even in its low-risk concentrations. Today, photocatalytic removal methods has received a great deal of attention in comparison with other methods of removing pollutants. Therefore, the present study aimed to determine the efficiency of removal of xylene vapor from airflow using photocatalytic property of titanium dioxide on ZSM-5 zeolite.

Materials and Methods: In this experimental study, the characteristics of the catalysts were determined using Brunauer-Emmett-Teller, X-ray diffraction (XRD), and scanning electron microscopy scanning (FESEM). Xylene vapors were produced using a dynamical condenser system and the efficiency of xylene vapor depletion was investigated using UV / ZSM-5 / $\mathrm{TiO}_{2}$.

Results: The obtained results of the images and spectra from XRD, EDS, and FESEM showed good signs of immobilization. The findings revealed that the removal efficiency was decreased by increasing the concentration from $50 \mathrm{ppm}$ to $150 \mathrm{ppm}$ and increasing the flow rate from 0.3 to 0.5 . The removal efficiency at concentrations of 50, 100, and 150 was $35.46 \%$, $22.70 \%$, and $17.37 \%$, respectively.

Conclusion: The results showed that the use of composite substrates increases the efficiency of photocatalytic removal, and it is suggested that these adsorption and photocatalytic combination systems can be used to remove other volatile organic compounds in the gas phase.

Keywords: Nanoparticles; Photocatalytic Removal; $\mathrm{TiO}_{2}$; Xylene; ZSM-5 Zeolite 
dof: $10.21859 /$ johe.5.2.39

\section{بررسى حذف فتوكاتاليستى بخار زايلن از جريان هوا با استفاده از نانوذرات دىاكسيد تيتانيوم تثبيتشده بر روى زئوليت سنتزى نوع له}

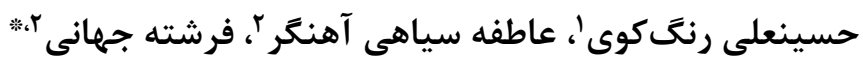
' مركز تحقيقات فناورىهاى زيست محيطى، دانشكاه علوم يزشكى جندى شايور اهواز، اهواز، ايران و استاديار كروه مهندسى بهداشت حرفهاى، دانشكده

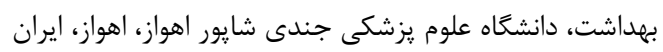

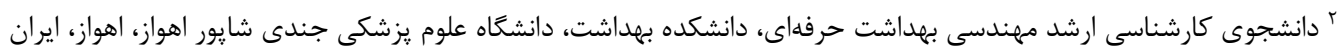
ز نويسنده مسئول: فرشته جهانى، دانشكده بهداشت، دانشكاه علوم يزشكى جندى شايور اهواز، اهواز، ايران. ايميل: jahani.f71@gmail.com جكيده سابقه و هدف: زايلن يك تركيب آلى فرار است كه داراى كاربرد وسيعى در صنايع مختلف مىباشد. اين

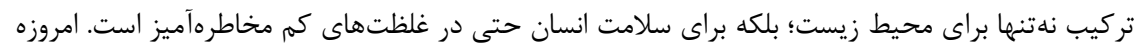

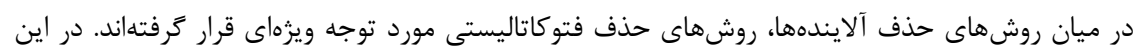

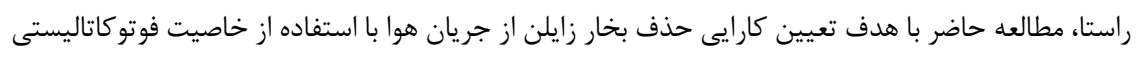

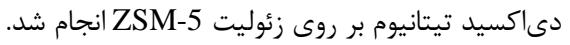

تاريخ دريافت مقاله: تاريخ يذيرش مقاله:

تمامى حقوق نشر براى دانشعاه علوم يزشكى همدان محفوظ است.

BET: مواد و روش ها: در اين مطالعه تجربى ويزَى هاى كاتاليستهاى توليدشده با استفاده از آناليزهاى

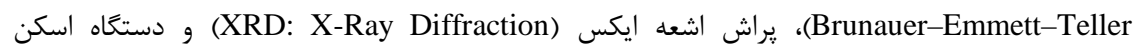
ميكروسكوٍ الكترونى روبشى (FESEM: Field Emission Scanning Electron Microscope) تعيين

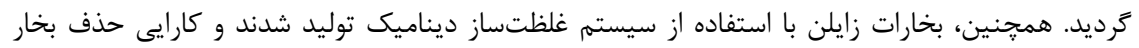
زايلن با استفاده از UV/ZSM-5/TiO2

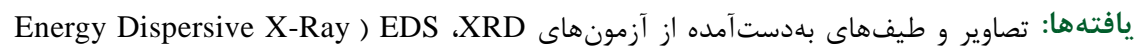

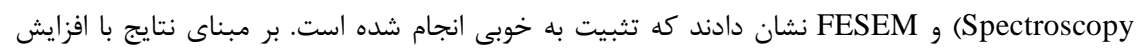

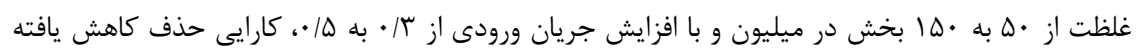

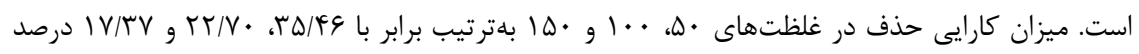
بهدست آمد. نتيجهَيرى: نتايج نشان دادند كه استفاده از بسترهاى تركيبى، كارايى حذف فتو كاتاليستى را افزايش مي دهد؛

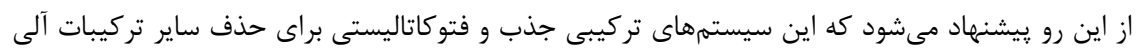
فرار در فاز كازى مورد استفاده قرار كيرند.

وازگَان كليدى: حذف فتوكاتاليستى؛ دىاكسيد تيتانيوم؛ ذرات نانو؛ زايلن؛ زئوليت سنتزى نوع ه

مقلهمه

مورد استفاده قرار مى گيرند [ب]]. مهمترين منابع انتشار اين

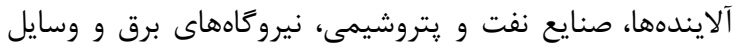

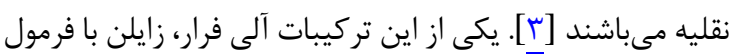

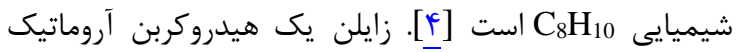
بىرنت با طعم شيرين مىباشد كه به راحتى قابل اشتعال است.

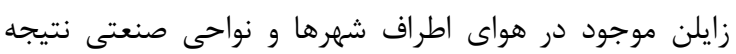

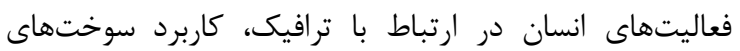

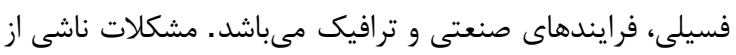
مواجهه با اين تركيبات باعث جلب توجه به اين ماده خطرناك
يكى از دستاوردهاى مهلم بشر در سالهاى اخير، رشد سريع

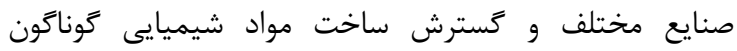

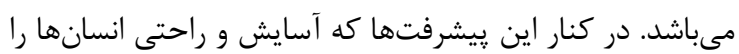

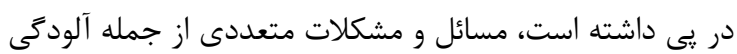
زيست محيطى و بلويزه آلودگى هوا ايجاد شده است كه به به تدريج به يكى از دغدغههاى مهم بشر تبديل شده است [1]

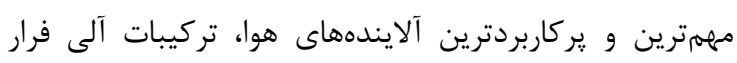
(VOCs: Volatile Organic Compounds) تركيبات در بسيارى از صنايع بهعنوان حلال و سوختهاى مايع 
مدت • ب دقيقه درون التراسونيك قرار گرفت. سيس به مدت دو ساعت توسط شيكر هم زده شد تا نانوذرات

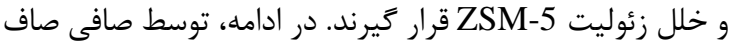

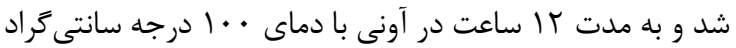
خشك كرديد. سيس براى تثبيت

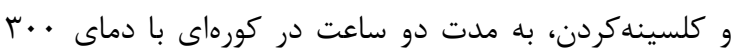
درجه سانتى

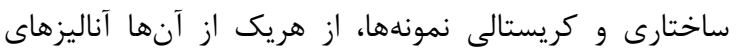
يراش اشعه ايكس (EDS و XRD) و تصاوير دستخاه اسكن

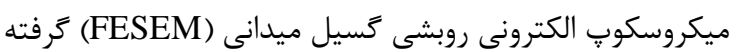
شد. تعيين مساحت سطحى ويزه جاذب و كاتاليستها با استفاده

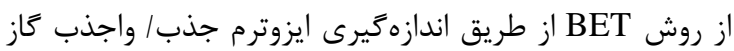

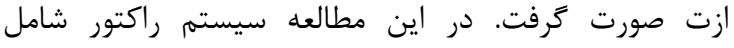

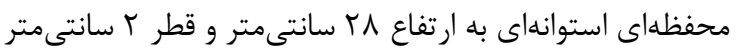

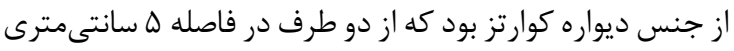
يك ورودى و يك خروجى داشت. در داخل راكتور استوانهاى، 1

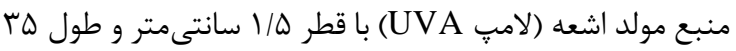

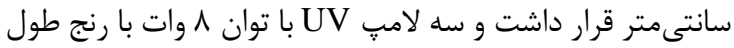

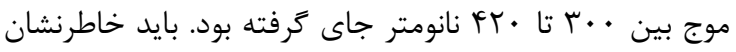
ساخت كه دماى داخلى راكتور تحت تابش دماى طبيعى اتاق

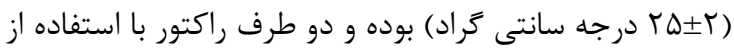
كه در برابر ماده شيميايى (Polytetraflouroethylen) PTFE زايلن مقاوم است، درزبندى شده بود و اندازهكيرى بخارات زايلن

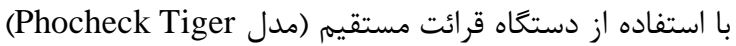

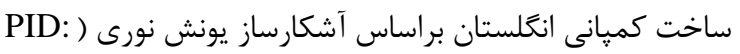

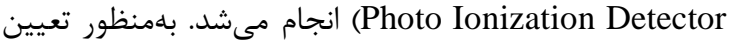
ميزان كارايى بستر در فرايند حذف فتوكاتاليستى، ب گرم از

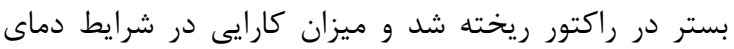
محيطى r r r د درجه سانتى

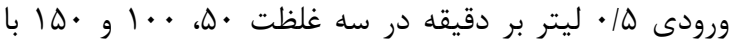

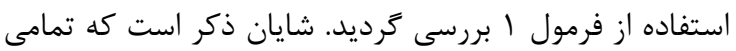

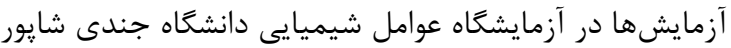

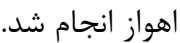

\section{يافته ها}

نتايج حاصل از آناليز BET در جدول ا ارائه شده است. با نقا

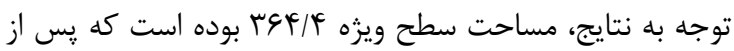

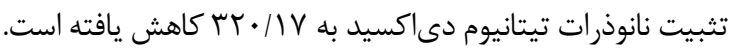

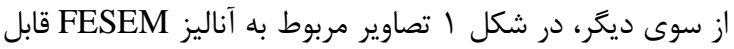

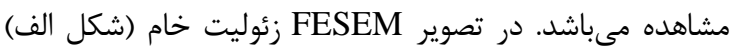
ذرات بلهصورت كروى و شفاف مشاهده مى مردند و در درو تصوير زئوليت يوشش دادهده (شكل ب) ذرات بهصورت تودهاى و كلوخه

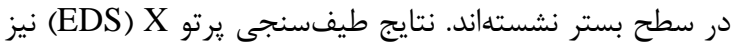

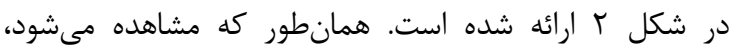

شده است [ه]. با پيشرفت روزافزون صنايع و كاربرد فراوان

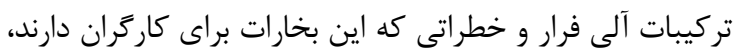

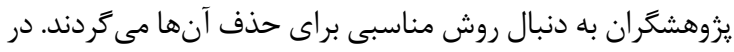

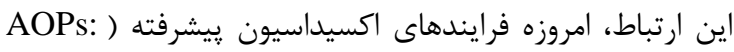
(Advanced Oxidation Processes

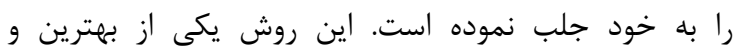

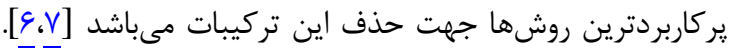

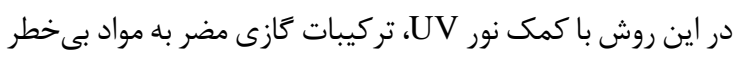
ناندر ات نانوذرات به همراه اشعه UV از جمله فرايندهاى مؤثر و ارزان در

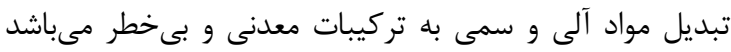

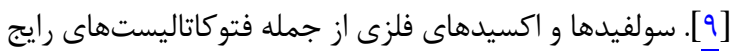

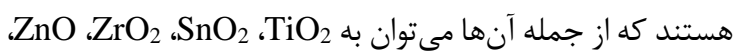
CdS ، $\mathrm{Fe}_{2} \mathrm{O}_{3}$ فوتوكاتاليستها

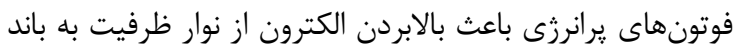

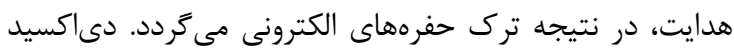

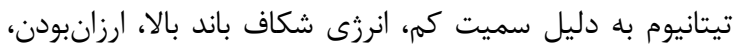
سازكارى با محيط زيست، يايدارى شيميايى و فعاليت بالا براى لئي حذف VOCs بهطور گستردهاى مورد استفاده قرار مي كيرد [11].

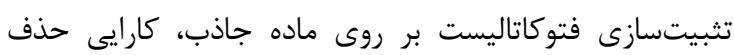

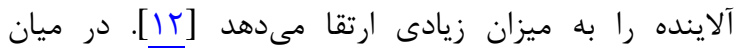

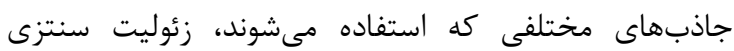

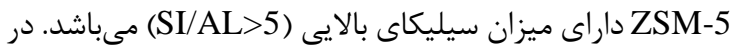
حال حاضر ساخت تعداد زيادى زئوليت با ميزان سيليكاى بالا به داله

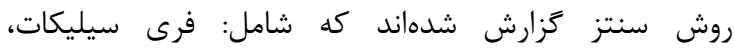

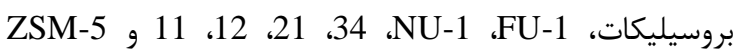
مىباشد كه از اين بين، سيليكاليت و ZSM-5 داراى اهميت تجارى هستند [1/1]. با توجه به به موارد بيانشده، مطالعه حاضر با هدف بررسى عملكرد نانوذرات دى هـاكسيد تيتانيوم

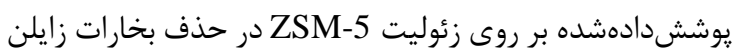

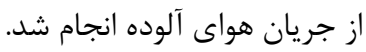

\section{مواد و روشها}

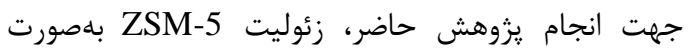

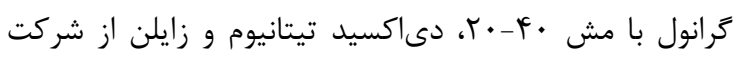

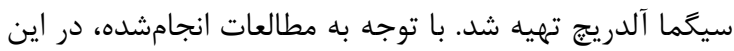

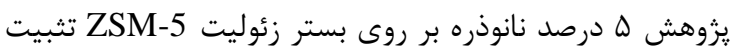

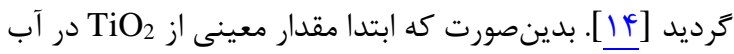

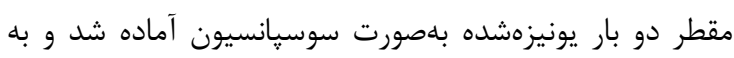

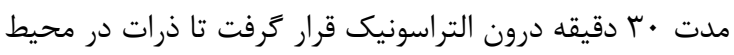

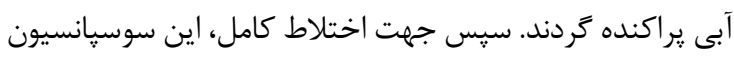
به مدت • r دقيقه توسط شيكر هم زده شد. در ادامه، مقدار

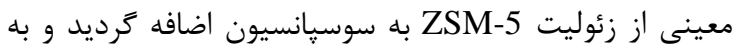




\begin{tabular}{|c|c|c|}
\hline $\mathrm{ZSM}-5 / \mathrm{TiO}_{2}$ & ZSM-5 & 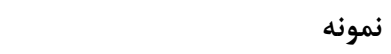 \\
\hline$r T \cdot / l V$ & req/F & سطح ويزه (متر مربع بر گرم) \\
\hline$r / r v \cdot \Lambda$ & $\Delta / \mu F F$ & ميانحين قطر حفرات (نانومتر) \\
\hline . /TG4 & $\cdot / 4911$ & حجم كل (سانتىمتر مكعب بر گرم) \\
\hline
\end{tabular}
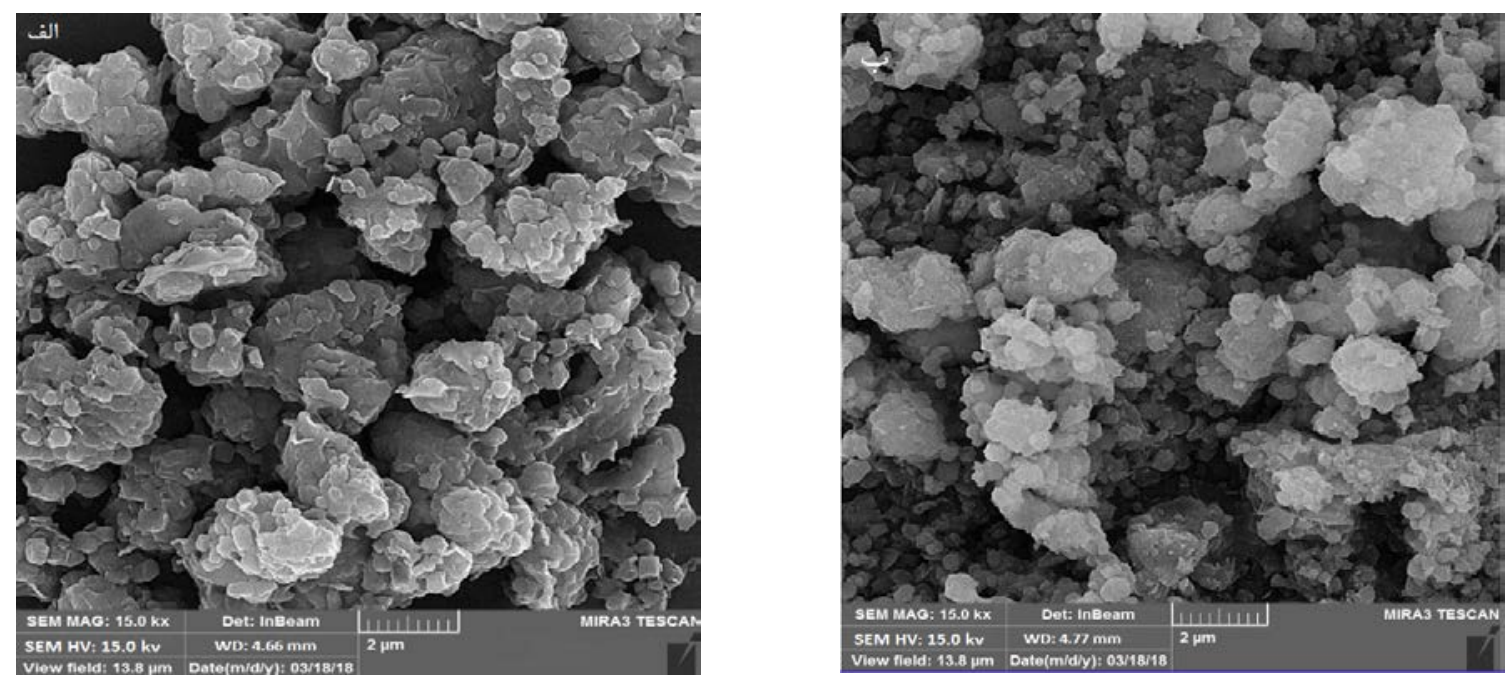

شكل ا: تصاوير FESEM: الف. زئوليت ZSM-5 ب. ZSM-5/TiO

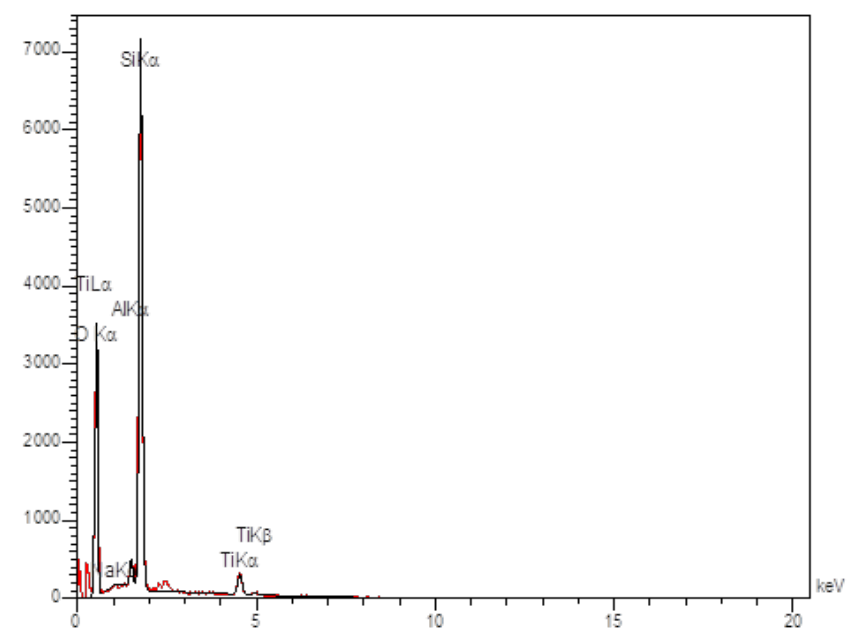

\begin{tabular}{|c|c|c|c|c|c|c|c|c|c|c|c|c|c|c|c|}
\hline Elt & Line & Int & Error & K & $\mathbf{K r}$ & W\% & A\% & ZAF & Formula & Ox\% & Pk/Bg & Class & LConf & HConf & Cat\# \\
\hline $\mathrm{O}$ & $\mathrm{Ka}$ & 808.2 & 76.4416 & 0.4320 & 0.2490 & 59.25 & 72.71 & 0.4202 & & 0.00 & 107.35 & A & 58.49 & 60.01 & 0.00 \\
\hline $\mathrm{Na}$ & $\mathrm{Ka}$ & 5.2 & 0.1091 & 0.0011 & 0.0006 & 0.13 & 0.11 & 0.4614 & & 0.00 & 2.12 & B & 0.11 & 0.16 & 0.00 \\
\hline $\mathrm{Al}$ & Ka & 108.4 & 17.2646 & 0.0203 & 0.0117 & 1.61 & 1.17 & 0.7262 & & 0.00 & 3.68 & B & 1.55 & 1.67 & 0.00 \\
\hline $\mathrm{Si}$ & $\mathrm{Ka}$ & 2478.8 & 17.2646 & 0.4857 & 0.2799 & 34.65 & 24.22 & 0.8077 & & 0.00 & 43.15 & A & 34.40 & 34.91 & 0.00 \\
\hline $\mathrm{Ti}$ & Ka & 127.3 & 0.7674 & 0.0609 & 0.0351 & 4.35 & 1.78 & 0.8071 & & 0.00 & 6.56 & A & 4.21 & 4.49 & 0.00 \\
\hline
\end{tabular}

شكل r: نتايج حاصل از EDS نمونه

ه/ • ليتر در دقيقه در شكل \& مورد مقايسه قرار گرفته است.

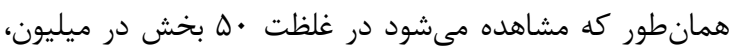

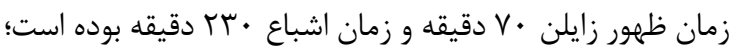

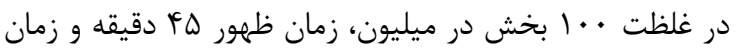

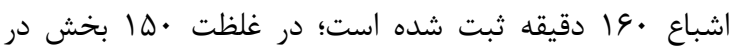

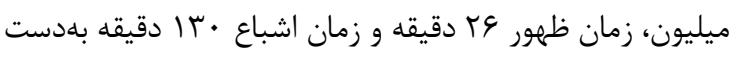

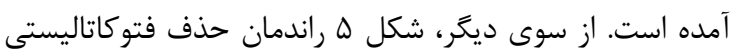

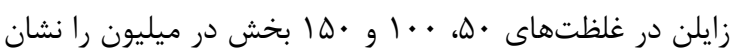

زئوليت يوششدادهشده حاوى ه/ L/ درصد تيتانيوم بوده است.

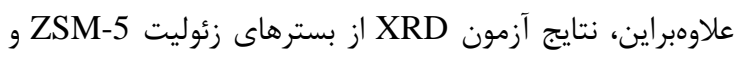
ZSM-5/TiO 2 مشخصه فاز دارند. وجود ريكى نشاندهنده توليد موفقيت آميز كاتاليست ZSM-5/TiO

ميزان كارايى جذب بخارات زايلن توسط بستر زئوليت

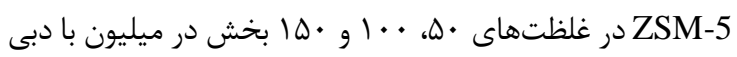



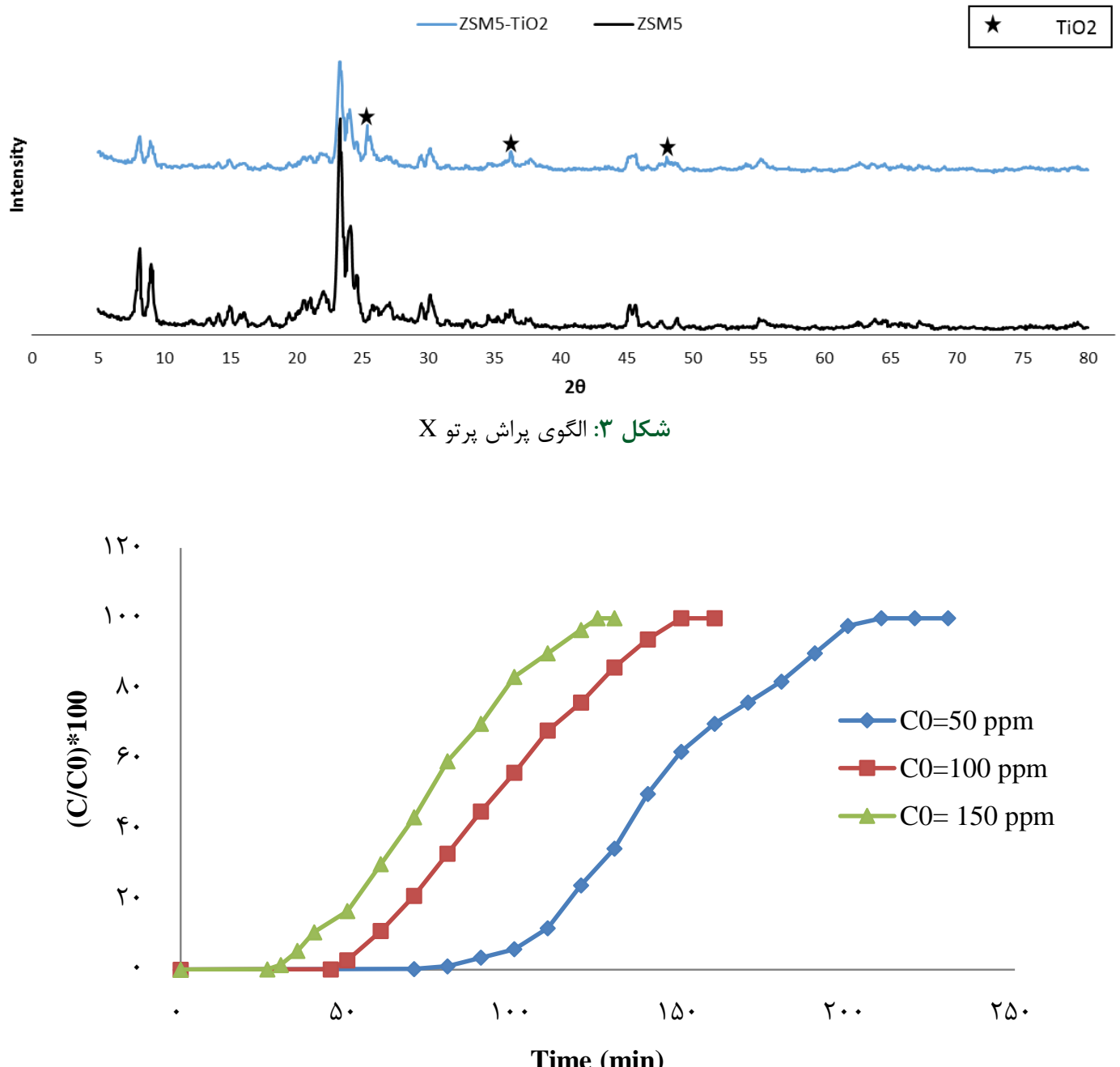

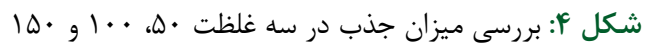

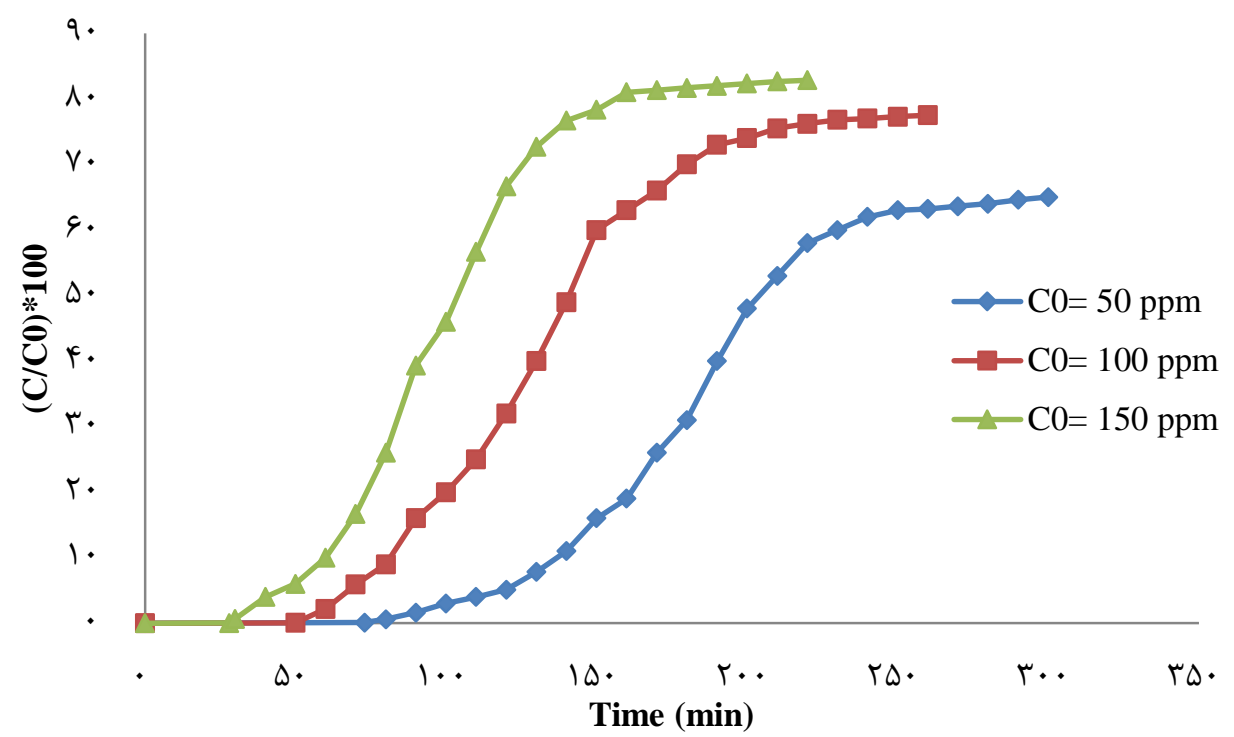

شكل ه: كارايى حذف فتوكاتاليستى بخار زايلن تحت غلظتهاى گَوناگون در فرايند UVSM5-TiO2

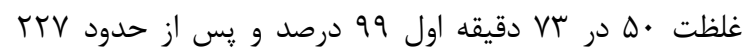

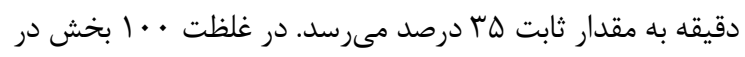

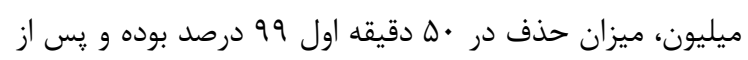

مى دهد. بر مبناى اين شكل با افزايش غلظت از •له به • لها،

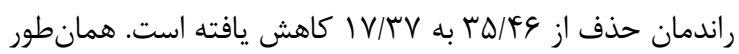
كه در اين شكل مشاهده مىشود، ميزان كاهش بخارات زائ زايلن در 


$$
\text { درصد بهدست آمد [11].]. }
$$

دما و رطوبت از ديخر فاكتورهايى هستند كه بر كارايى

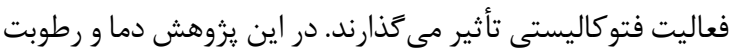

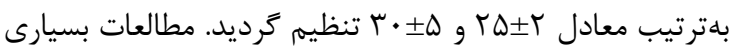
دماى محيط را مناسبترين دما جهت فرايند حذف فتوكات كاتاليست

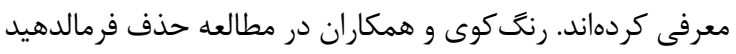

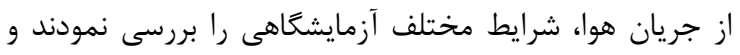

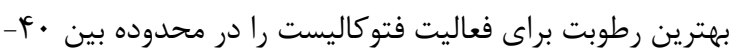
• ب درصد دانستند [19].

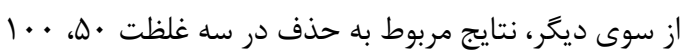

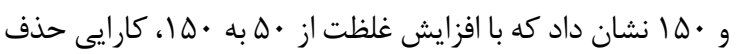

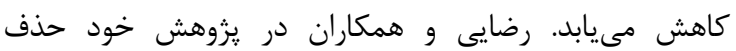

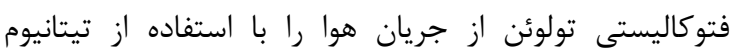

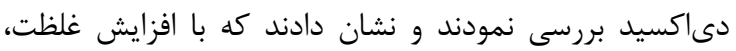

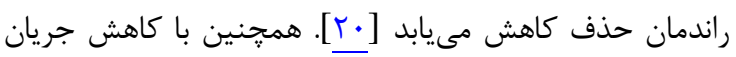

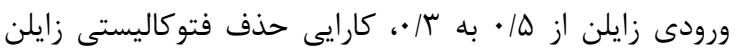

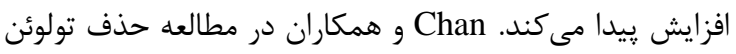

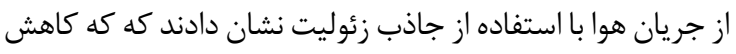

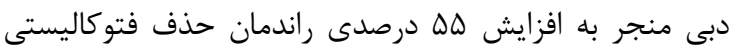

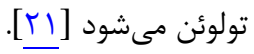

\section{نتيجه تيرى}

از نتايج بهدستآمده از اين مطالعه جنين استنباط مىشود

كه تثبيت ذرات نانوماده نيمهرساناى

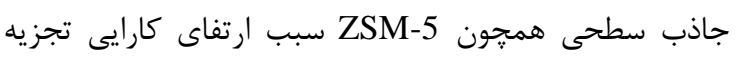
آلاينده زايلن در هوا مىشود؛ بهطورى كه بر مبر مبناى نتايج، فرايند ZSM-5/TiO $2 / \mathrm{UV}$ بنابراين استفاده از فرايند UV/ZSM5-TiO

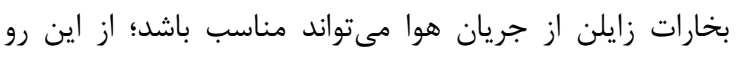

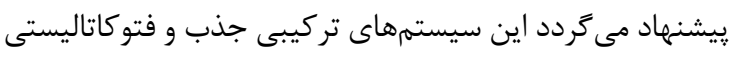

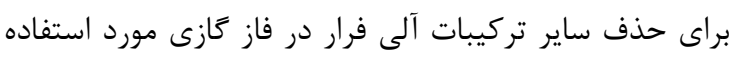

$$
\text { قرار گيرد. }
$$

\section{تشكر و قلر دانى}

يزوهش حاضر در قالب پاياننامه كارشناسى ارشد با شماره طرح ETRC-9605 از سوى حوزه معاونت يزوهشى داضى دانشعاه

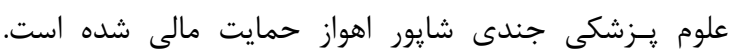

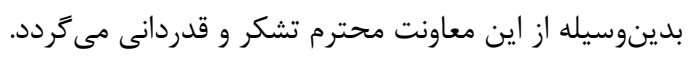

\section{REFERENCES}

1. Cooper CD, Alley FC. Air pollution control: a design approach. New York: Waveland Press; 2010.

2. Khan FI, Ghoshal AK. Removal of volatile organic compounds from polluted air. J Loss Prev Proc Ind. 2000;13(6):527-45. DOI: 10.1016/S0950-4230(00)00007-3

3. Domeño C, Rodríguez-Lafuente A, Martos JM, Bilbao R, Nerín C. VOC removal and deodorization of effluent gases from an

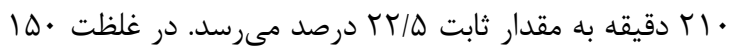

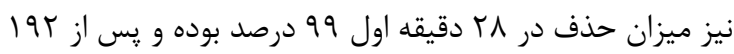

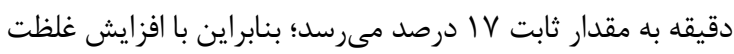

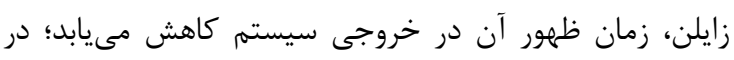

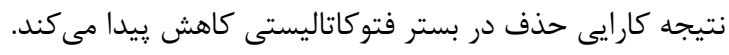

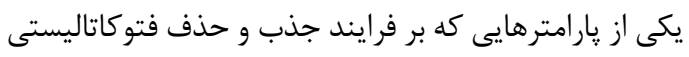

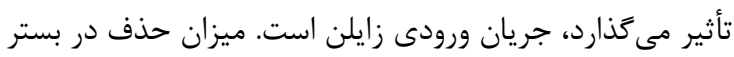
ZSM-5/TiO

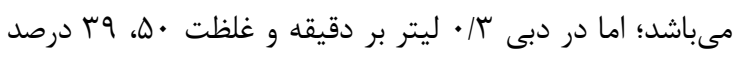

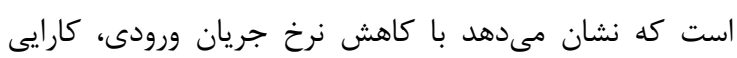
فتو كاتاليستها افزايش يافته است.

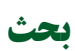

سطح كاتاليزورى مهمترين عامل فعاليت فتوكاليست است.

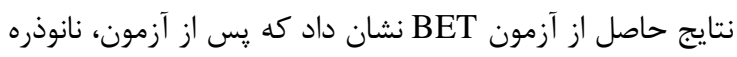

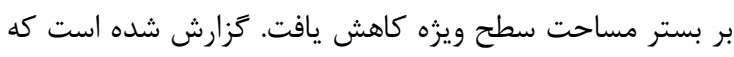

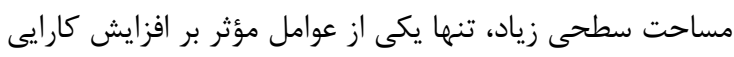

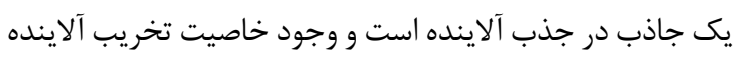

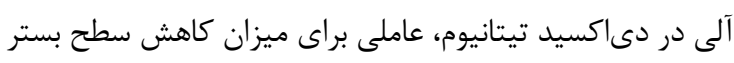

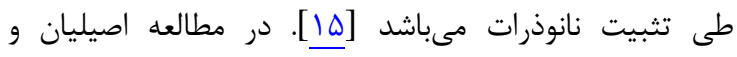

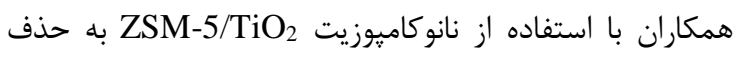

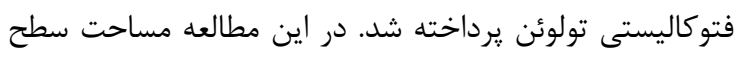

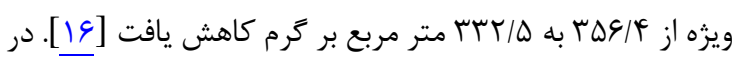

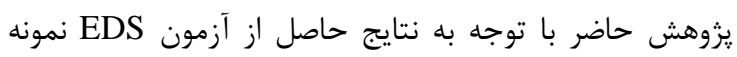
ZSM-5/TiO

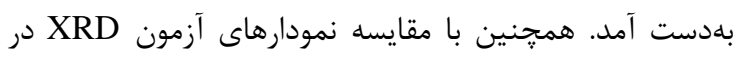

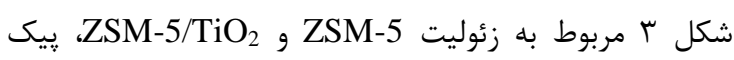

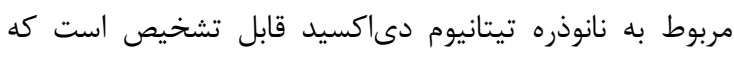

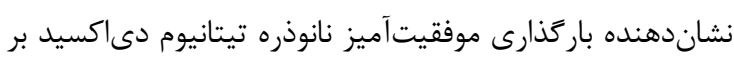

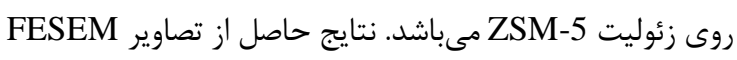
نيز اين باركذارى را تأييد مى كنند. در اين مطالعه نانوذرات با نسبت ه درصد وزنى بررسى شدند و زئوليت گرديد كه اين مقدار باركذارى با توجه به مطالعات انجامشده قابل فرديل

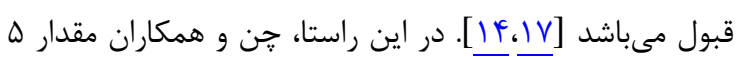

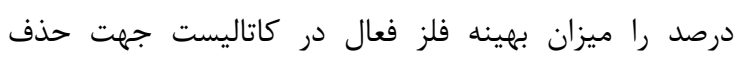

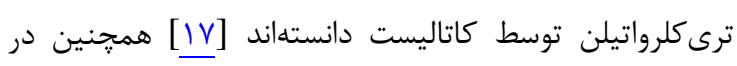
يزوهشى كه توسط رنغ كوى و همكاران انجام شد، ميزان بهينه توسئ

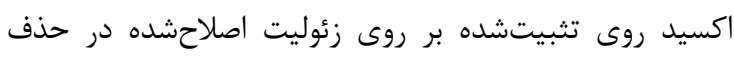

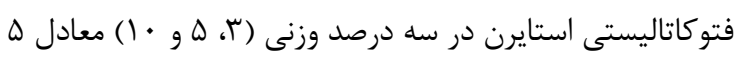

industrial plant by photo-oxidation, chemical oxidation, and ozonization. Environ Sci Technol. 2010;44(7):2585-91. PMID: 20192167 DOI: 10.1021/es902735g

4. Health Division of Physical Sciences. NIOSH, Manual of Analytical Methods. US Department of Health and Human Services, Public Health Service, Centers for Disease Control and Prevention, National Institute for Occupational Safety 
and Health, Division of Physical Sciences and Engineering; 1994.

5. Gariazzo C, Pelliccioni A, Di Filippo P, Sallusti F, Cecinato A. Monitoring and analysis of volatile organic compounds around an oil refinery. Water Air Soil Pollut. 2005;167(14):17-38.

6. Thiruvenkatachari R, Vigneswaran S, Moon IS. A review on UV/TiO 2 photocatalytic oxidation process (Journal Review). Korean J Chem Eng. 2008;25(1):64-72.

7. Benoit-Marquié F, Wilkenhöner U, Simon V, Braun AM, Oliveros E, Maurette MT. VOC photodegradation at the gassolid interface of a TiO2 photocatalyst: Part I: 1-butanol and 1-butylamine. J Photochem Photobiol A Chem. 2000; 132(3):225-32. DOI: 10.1016/S1010-6030(00)00196-9

8. Mohamed RM, McKinney DL, Sigmund WM. Enhanced nanocatalysts. Mater Sci Eng Rep. 2012;73(1):1-13. DOI: 10.1016/j.mser.2011.09.001

9. Cho SP, Hong SC, Hong SI. Photocatalytic degradation of the landfill leachate containing refractory matters and nitrogen compounds. Appl Catalysis B Environ. 2002;39(2):125-33. DOI: 10.1016/S0926-3373(02)00079-6

10. Hoffmann MR, Martin ST, Choi W, Bahnemann DW. Environmental applications of semiconductor photocatalysis. Chem Rev. 1995;95(1):69-96. DOI: 10.1021/cr00033a004

11. Wu WQ, Xu YF, Rao HS, Su CY, Kuang DB. Multistack integration of three-dimensional hyperbranched anatase titania architectures for high-efficiency dye-sensitized solar cells. J Am Chem Soc. 2014;136(17):6437-45. PMID: 24725076 DOI: $10.1021 / \mathrm{ja} 5015635$

12. Nezamzadeh-Ejhieh A, Khorsandi S. Photocatalytic degradation of 4-nitrophenol with $\mathrm{ZnO}$ supported nanoclinoptilolite zeolite. J Ind Eng Chem. 2014;20(3):937-46. DOI: 10.1016/j.jiec.2013.06.026

13. Baerlocher C, McCusker LB, Olson DH. Atlas of zeolite framework types. New York: Elsevier; 2007.
14. Nakhaeipour M, Shojaee FA, Najarian F, Safinezhad M, Irvani $\mathrm{H}$. Determining the efficiency of zsm5-zeolite impregnated with nanoparticles of titanium dioxide in the photocatalytic removal of styrene vapors. J Occupat Hyg Eng. 2017;3(4):61-7. DOI: 10.21859/johe-03048

15. Zhu YP, Li M, Liu YL, Ren TZ, Yuan ZY. Carbon-doped ZnO hybridized homogeneously with graphitic carbon nitride nanocomposites for photocatalysis. $J$ Phys Chem C. 2014;118(20):10963-71. DOI: 10.1021/jp502677h

16. Asilian Mahabady $\mathrm{H}$, Khavanin A, Aresoomandan S. Efficiency evaluation of the photocatalytic removal of toluene vapour by titanium dioxide nanoparticles immobilized on ZSM-5 zeolite. Iran Occupat Health. 2018;15(1):17-25. [Persian]

17. Chen JC, Tang CT. Preparation and application of granular $\mathrm{ZnO} / \mathrm{Al} 2 \mathrm{O} 3$ catalyst for the removal of hazardous trichloroethylene. J Hazard Mater. 2007;142(1-2):88-96. PMID: 16949739 DOI: 10.1016/j.jhazmat.2006.07.061

18. Rangkooy HA, Pour MN, Dehaghi BF. Efficiency evaluation of the photocatalytic degradation of zinc oxide nanoparticles immobilized on modified zeolites in the removal of styrene vapor from air. Korean J Chem Eng. 2017;34(12):3142-9. DOI: 10.1007/s11814-017-0174-2

19. Khoopaie AR, Jafari AJ, Khavanin A, Rezaee A, Rangkooy HA. A study on photocatalytic removal of formaldehyde from air using zno nanoparticles immobilized on bone char. J Qum Univ Med Sci. 2013;7(2):27-34. [Persian]

20. Rezaee A, Khavanin A, Saraf Mamoori R, Hajizadeh E. Elimination of toluene by application of ultraviolet irradiation on TiO2 nano particles photocatalyst. J Mil Med. 2007;9(3):217-22. [Persian]

21. Chao CY, Kwong CW, Hui KS. Potential use of a combined ozone and zeolite system for gaseous toluene elimination. $J$ Hazard Mater. 2007;143(1-2):118-27. PMID: 17030416 DOI: 10.1016/j.jhazmat.2006.08.077 